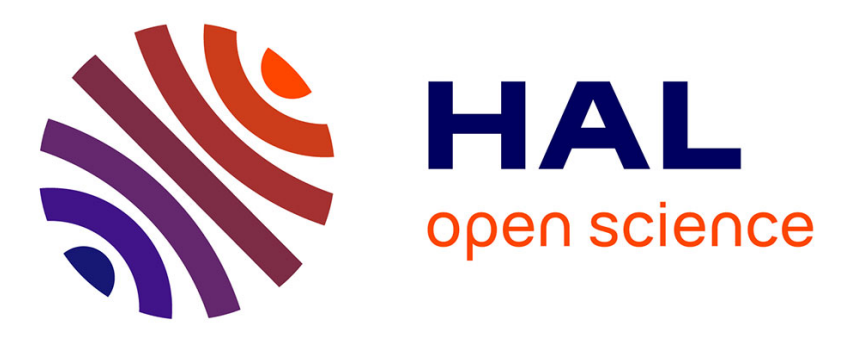

\title{
ICT-Based Challenges of Repurposing a Single-Campus Course to Multi-campus Settings: A Pragmatic Case Study
}

\author{
Abdullah Bahmani, Rune Hjelsvold, Birgit Rognebakke Krogstie
}

\section{To cite this version:}

Abdullah Bahmani, Rune Hjelsvold, Birgit Rognebakke Krogstie. ICT-Based Challenges of Repurposing a Single-Campus Course to Multi-campus Settings: A Pragmatic Case Study. 18th Conference on e-Business, e-Services and e-Society (I3E), Sep 2019, Trondheim, Norway. pp.641-653, 10.1007/9783-030-29374-1_52 . hal-02510136

\author{
HAL Id: hal-02510136 \\ https://hal.inria.fr/hal-02510136
}

Submitted on 17 Mar 2020

HAL is a multi-disciplinary open access archive for the deposit and dissemination of scientific research documents, whether they are published or not. The documents may come from teaching and research institutions in France or abroad, or from public or private research centers.
L'archive ouverte pluridisciplinaire HAL, est destinée au dépôt et à la diffusion de documents scientifiques de niveau recherche, publiés ou non, émanant des établissements d'enseignement et de recherche français ou étrangers, des laboratoires publics ou privés.

\section{(c)(1)}

Distributed under a Creative Commons Attribution| 4.0 International License 


\title{
ICT-based challenges of repurposing a single-campus course to multi-campus settings: a pragmatic case study
}

\author{
Abdullah Bahmani ${ }^{1}$ () , Rune Hjelsvold ${ }^{2}$ (D) , and Birgit Rognebakke Krogstie ${ }^{3}$ (C) \\ 1,2,3 The Norwegian University of Science and Technology (NTNU), Norway \\ 1,2,3 [Abdullah.Bahmani, Rune.Hjelsvold, \\ Birgit.R.Krogstie] entnu.no
}

\begin{abstract}
Studies show that the integration of ICT in education is suffering from some barriers at student, teacher, and university level. This also holds for multicampus education, as ICT is one of the main ingredients for sharing education among campuses. In this study, through a pragmatic case study at the context of a Scandinavian multi-campus university and with the help of activity theory, we examined the challenges of offering a single-campus course to students at multiple campuses by using ICT for lecture sharing, without further adjustments. Data for this study is collected from different sources (teachers, teaching assistants, and students) through interviews and observations and from an online questionnaire. Our findings suggest that repurposing a single-campus course to a multicampus one without having clear and pre-defined rules poses some challenges for the different stockholders and influences their relations, resulting in negative impacts on teaching and learning processes and teacher and students' satisfaction. Therefore, we conclude that there should be careful planning with a clear set of rules, including technology training and preparation for teaching staff, students, and technical staff. Staff structure may also need to be modified to accommodate the additional needs for technical support.
\end{abstract}

Keywords: ICT, lecture video streaming, multi-campus education, challenges, Activity Theory.

\section{Introduction}

There are several studies dealing with the integration of ICT in education [1-6]. Despite the number of studies on ICT and education, our understanding of how multi-campus education can be mediated by ICT is still limited [7-11]. Multi-campus education differs from MOOC, or Massive Open Online Course, which provides education for a massive number of learners at any geographical location without "the need to satisfy formal entry requirements" [12]. Multi-campus education as a learning environment provides education for students at each campus, aiming to increase the learning quality by having collaboration among people from different campuses. Offering multi-campus education in universities, particularly those that have multiple campuses dispersed in different geographical locations, promises new opportunities to students, teachers, and universities [7, 13-15]. Therefore, multi-campus education deserves more attention. 
Much of the research on multi-campus education is concerned with the implementation process and provides insight into how to use different ICT devices for multi-campus courses and their pros and cons [7, 8, 13, 14, 16-18]. Only a few studies have investigated issues relating to the application of ICT in multi-campus education like [1921]. Research to date has not determined a fuller picture on the issues, in particular, those related to offering a single-campus course in a multi-campus setting. In our previous research [22] we tried to understand the challenges of repurposing single-campus courses to the multi-campus setting by observing five different cases at a Scandinavian multi-campus university. This study examines an in-depth analysis of one of these case studies in which a course - delivered in the single-campus mode for several semesters - was repurposed to a multi-campus setting. We will be using the activity theory and will analyze both qualitative and quantitative data. In this case, the repurposing mainly happened through the use of ICT; and only minor modifications were done otherwise. This posed some challenges to the course stakeholders and influenced their outcome. The research questions that we explicitly address in this study are the following:

- First, what are the challenges caused by extending a single campus course to a multicampus setting with the use of ICT?

- Then, how are different teaching staff (teachers and TAs), students, technical staff, administrative rules affected by these challenges?

- Finally, what are the necessary actions to take, when planning for a multi-campus course?

The significance of the contributions of this paper is threefold: First, it helps the readers to get an overview of multi-campus course delivery with the presence the ICT to share education among different campuses. Second, it increases the readers' awareness, particularly the administration in multi-campus universities, about the impacts on different elements of the multi-campus education activity. Third, this paper heightens our practical and theoretical awareness of the importance of examining both technological and human/social aspects of multi-campus education.

\section{$2 \quad$ Literature review}

\subsection{ICT in education}

These days, ICT is an indispensable part of our lives, and we can see its footprints in all aspects of our life, such as in business [23], health[24], retail and marketing [25], money [26], and banking [27]. Regardless of a dynamic role in society, ICT, however, has fewer usage in education [28].

According to Bingimlas [2], computers found their way into schools at the beginning of the 1980s. Some researchers proposed that ICT will be an essential portion of education in the future, such as [2, 29]. They believed that ICT could play an active role in learning and teaching activities $[2,29]$ and that ICT will provide interaction, flexibility, and innovation [30]. However, ICT integration in education has just been considered "a simple matter of putting computers in classrooms" [30]. Some researcher 
argued that, so far, ICT has had a minor impact on education regardless of the vast amount of money spent on ICT in education $[6,31]$.

In response to the question "Why ICT has a minor role in education?", Bingimlas [2] classified the related barriers into teacher-level (lack of teachers' confidence and competence, resistance to change and negative attitudes), and school-level (lack of time, effective learning, accessibility, and technical support) [2]. Dubé, et al. [32] reported teachers' stress as an obstacle when confronted with the new technology. Some studies focus on challenges at the student-level (lack of technical skill, lack of academic advisors, lack of feedback from the teacher, lack of interaction with other students and teachers ) [1].

\subsection{ICT and Multi-Campus Universities}

[33] distinguished between four broad types of multi-campus universities in terms of their size, structure, and relationship between their campuses. One of the unique challenges that Groenwald [33]identified for leaders in multi-campus universities is the quality assurance in campuses, particularly having curricula and courses with the same quality in all parts. In the context of this study, we are interested in multi-campus education to address this challenge.

Two options for having multi-campus education are replication and integration. The former refers to a situation where universities provide all the courses and programs in all campuses, while the latter refers to a flexible model of education that campuses can have collaboration with each other to share the courses or even study programs running from one to others [34]. There are several reasons for why universities offer multicampus education. Reasons include equal access to the study programs for students living in different places, bringing students and university staff with different experiences together in a single united place [34], multi-mode of learning with flexible course delivery option for the students, preparation for the workplace by studying in online learning mode [7] reducing the costs, and having more students [15].

According to Ebden [7], multi-campus integration requires ICT support. Some studies reported the use of ICT devices for synchronous [35, 36] and asynchronous [8, 14] multi-campus education. Besser [37], however, believed that it is not just about installing devices and using them. He recommended that there should be careful planning for technical and physical set-up, support for the teachers, and think of change in teaching strategies. Reilly, et al. [38] proposed a teachers' development program through a community of practice.

The literature also shows that multi-campus education raises a new set of related challenges [7]. This includes the lack of ICT knowledge of teachers and students [20], logistical barriers, lack of interaction between teacher and students [21], students' engagement [39], remote students' feeling of isolation [40], lack of rules [16, 41, 42] and careful planning [43], technical failure and lack of sufficient technical support [7, 39, 44]. The existing literature discusses some of the challenges in multi-campus education, but no prior study gives a holistic view of the process and related challenges. In this research, therefore, through a pragmatic case study and with the help of the activity theory, we examined the related challenges and their impacts on different stakeholders 
in the education process. In addition, we identified the necessary actions to consider when planning for offering a multi-campus course.

\subsection{Theoretical framework}

In this study, we adopted the activity theory [45] and, in particular, the activity system [46], as it gives a holistic understanding of a "real-world situation." The activity system has six elements (Tools, Subjects, Object, Rules, Commu-

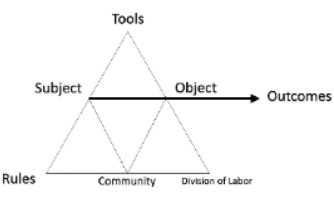

Fig. 1. Activity System nity, and Division of Labor) as shown in Fig. 1. A critical and central part of the activity theory is contradictions. Contradictions may arise when an external force modifies an element of the activity system, which causes potential imbalances among the elements. Some studies have used the activity theory (particularly the complete activity system) in the education context $[5,47,48]$.

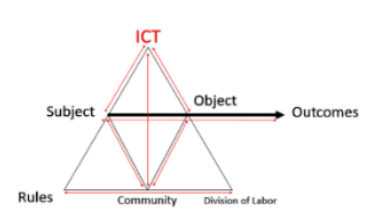

Fig. 2. An imbalance in the activity system

Offering a single-campus course in a multi-campus setting implies a need to employ ICT devices to provide multi-campus education. Based on the activity system, the integration of ICT into the single-campus education activity is an external force that brings an imbalance to the system. The presence of new tools affects elements of the system and their relations and consequently, the outcome of the activity system, as shown in Fig. 2.

\section{$3 \quad$ Research approach}

\subsection{Pragmatic case study}

This paper adopts a pragmatic case study [49]. In pragmatic studies, researchers try to have an experiment to gain the experience and then interpret the result. It is a mixed method [50] approach, which includes (a) qualitative data; (b) quantitative data, and (c) interpretations of data made in a scientific, theoretical, empirical and peer-reviewed context.

\subsection{Case setting}

Recently, a Scandinavian university has been merged with several colleges situated at different geographical places. The merger is intended to result in improved quality of teaching and research that extends the sum of the parts. This means that multi-campus courses and study programs should utilize and combine the strengths of each campus. Sometimes, however, the resources are unevenly distributed among the campuses. In

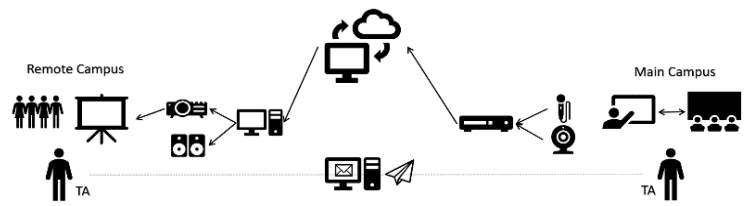

Fig. 3. The multi-campus setup 
the case of one course offered on two campuses in Fall 2018, there was a lack of academic staff at one campus. Accordingly, it was decided to repurpose the course to the multi-campus setting with the help of ICT, as shown in Fig. 3. Mediasite [51] was used for this course, providing unidirectional video streaming with a close to 30-second delay. This setup was chosen because there were already Mediasite installations present and available without the need for additional investments in ICT. Two TAs were hired to help the process of teaching and learning at both campuses. They had constant communication with each other via a specific social network, SMS, and phone call as well as the internal mail service. Both TA were master's students.

\subsection{Data collection and analysis methodology}

In this study, we used qualitative as well as quantitative data () from multiple sources (a teacher, TAs, and students). The data was gathered from interviews, observation, and an online questionnaire. Data triangulation helped us to validate and align the findings. Having different types of data gathered through different methods from multiple sources can help us to have a complete picture of the question we have under our investigation [52]. The semi-structured interviews with the teaching staff were done in December 2018. The length of interviews was varying from 30 minutes to one hour. The recorded voice files were transcribed and then analyzed with Nvivo 12.0 pro.

Students $(n=200)$ from both campuses were invited to participate in an online questionnaire. The quantitative data were analyzed in line with the qualitative to align the findings. Forty-eight students completed the questionnaire. Written observations with a lesser degree analyzed to confirm and complete the overall data.

\section{$4 \quad$ Results}

The analysis of the interviews and questionnaire data unveiled challenges and tensions that can be considered as contradictions in the course viewed as an activity system:

Contradictions with rules. The lack of specific rules for multi-campus education in the university was a challenge for the teacher. The teacher did not receive any specialized training for multi-campus teaching.

[TEACHER] "All the material was new. I was not sure that I would finalize all the stuff."

No supplemental information or activities were offered to the students to prepare them for the new setting. 54\% of all students identified that they were informed about course setting by the teacher in the first session. Also, 37\% believed that they should have been given more information about the setting in advance, and some (20\%) asked for a more thorough introduction. 8\% of them specified that they did not feel a noticeable change in the teaching style, and 11 percent asked for more changes. TAs did not receive training either.

[TA] "I wasn't really informed about that ... I guess I got sort off thrown into it from the start"

TAs complained about the changes in logistics and GDPR. Changes in the logistics, in particular, the place of the class resulted in checking the devices before the session 
starts. Also, because of GDPR, the time of class had to be specified in advance, and it reduced the flexibility of the session length.

Contradictions with tools. There was a strong contradiction with tools for the teacher. The department had decided to repurpose a regular course, which previously had been offered for several semesters in a single-campus style. There was no technology training for the teacher. This was crucial in the presence of technical failure, as it stopped the lecture and made the teacher to be stressed and lose the focus on the teaching.

[TEACHER] "It [technical failure] is very important because when you are teaching... I get distracted, I get stressed, and it affects my teaching."

Of all students, 39\% confirmed that the technical failure happened in a few sessions, and $30 \%$ noticed that the teacher lost the focus on teaching. $29 \%$ did "agree" or "strongly agree" that the teacher should be trained for the new setting. Students also lost their attention while there were technical failures. This is confirmed by $13 \%$ of students in total. TAs also confirmed technical failure as a challenge for the process of teaching and learning.

[TA] "Where we had problems with the microphone not picking up, and lots of noise in the background, and stuff like that."

Besides, some lecture time was wasted because of technical failures (confirmed by $8 \%$ of students) and lack of tools in the classroom, particularly the lack of good microphone coverage in the main campus to ensure comprehensible audio playback at the remote campus.

[TEACHER] "I didn't have microphone, so I repeated the question."

In the main campus, a camera was installed to record the teacher and lecture room to give the remote students a feeling of "social presence" and engage them in the lecture. However, some students $(9 \%)$ had a problem with the class engagement, and it was not as what they expected. Therefore, they asked for "more class discussions." $9 \%$ of the main campus students reported that they opposed being recorded on the video. The new setup for the course hurt $12 \%$ of students; $8 \%$ percent stated that they needed to change their learning habit because of the multi-campus setting. From the viewpoint of the TAs, this negative impact originated from the technical failures:

[TA] "because it [was] demotivating to sit there with a bad image and terrible sound and just have to force yourself through the course.

The new setting also influenced TAs' work. They had to be in touch in order to be sure about the connection between the campuses. They did not get any training for the additional tools, and in many cases, they had to contact the technical staff. Technical staff also had problems with cross-campus communication tools. The technical staff did not have sufficient knowledge and skills to handle the technical problems when needed. TAs confirmed this challenge. Furthermore, in the TAs' point of view, the permission level of a person from technical staff, who showed up in the classroom to solve the problems was also critical.

[TA] "So at least make sure that there is one person with the right qualifications and admin right to fix the system if something is not working correctly."

Furthermore, the new tools influenced the relationship between teacher and students. Because of the technology, it was impossible to have a direct interaction between the lecturer and the main campus students on one side and the remote campus students on the other. 
[TEACHER]' It was not possible to have a dialogue, so it is hard to have any interaction with [remote campus]. It misses out something."

Students also identified some challenges in their relationship with the teacher. $23 \%$ reported that they could not participate in the class discussion and 19\% did not have the same amount of attention from the teacher in comparison with single-campus courses. The TAs also confirmed this:

[TA] "for the students I think the experience of being on the remote campus is probably a lot less interesting ... Because there is definitely a distance there that is hard."

Because of a unidirectional setup, remote students had to relay their question the local TA to be sent to the teacher via the TA at the main campus. This process was not only frustrating to the TAs, but it also took TAs' time:

[TA] "When students had questions. I had to make sure that the questions were sent up to

[Main campus] and to the lecturer and make sure that they got the answer. "

Contradiction with the division of labor. There was no local academic staff on the remote campus, and it was a challenge for the teacher to observe and assess the remote students.

[TEACHER] "I cannot be in two places at the same time. Then I would need some other academic person at the other place to do this thing."

The TAs complained about their role as it was different from what they expected.

[TA]" it is a fairly passive role, more of an administrative job, not so much of a teaching job."

Being busy with the logistics, the TAs were not able to create a productive relationship with the student, helping them in their course material, exercise, and class activities. Students confirmed this, and not a single student did receive help from the TAs. Even though the TAs had communications, they were facing some challenges in their communication because there was no rule for the TAs' communication, and they did not receive any training.

The unavailability of the technical staff during the sessions was another challenge for the TAs. Students (11\%) admitted that it is good to have someone from technical support staff in the classroom to solve the problems as soon as possible.

[TA] "The media center has not been available to actually help us with those problems during the lecture itself."

\section{Discussion}

This study aimed at identifying the challenges of integrating ICT into a traditional course to offer it in a multi-campus mode. We used activity theory as a "lens" to analyze both the qualitative and the quantitative data. It helped us to identify the elements of the related activity system and their relationships. With the help of activity theory, we, therefore, could determine the probable contradictions which are the results of changes in any elements.

For the first research question, we found that there were some challenges related to the rules, tools and the division of the labor. 
Contradictions with rules: several reports have shown that the lack of rules is a challenge for multi-campus courses [16, 41, 42]. Our findings support their work as in our case, after the merger, rules at the university level were not updated to cover multicampus activities. This includes the lack of ICT strategies, which is in line with the work of Stensaker, et al. [4]. We also found that external rules such as GDPR can be a challenge as it reduced the flexibility course delivery in our case.

Contradiction with tools: There were some challenges related to tools such as inadequate infrastructure, poor audio/video quality, technical failure, lack of interaction with remote students. These are consistent with the work of Divanoglou, et al. [39].

Contradiction with division labor. We found that lack of local academic staff was a source of a challenge for the teacher, especially for students' observation and examination. Our finding also shows that to keep the link between campuses alive, TAs were responsible for logistics and technology. They, therefore, had much less time for assisting the teacher and students in the process of education. Unavailability of technical staff in case of having technical problems was another challenge which agrees with the findings of other researchers Ebden [7], [39].

With respect to the second research question, lack of rules to cover multi-campus activities resulted in the selection of inadequate and inappropriate tools for lecture sharing. Video-streaming tools did not support two-way discussion between two campuses. So remote students did not have live interaction with the teacher. It made TAs have constant communication with each other to relay remote students' question to the teacher. This took much of the TAs time with the students, so the TAs could not establish productive relationships with teacher and students.

Lack of ICT-strategies resulted in starting the semester without having technical training and preparation for teaching staff and students. It was critical when there were technical problems, which made the teacher be stressed and distracted students from their learning. Our findings show that lack of local staff in the remote campus made teacher worry about the students' progress and outcome.

Concerning the third research question, we learned that the rules should be updated to cover multi-campus activities. Rules should contain technical and pedagogical training and preparation for teaching staff and students in the new learning spaces, which is in agreement with Andrews and Klease [20]. Also, there should be a 'well-defined institutional ICT-strategy," which supports ICT initiatives together with multi-campus activities. This can help in the selection of adequate and appropriate technology and infrastructure. This is in line with Stensaker, et al. [4]. We also learned that TAs should be offered technical training to deal with some of the minor technical problems. However, in order to solve more complex technical problems, there should be technical staff to specifically assigned to support the multi-campus courses. The availability of technical staff to deal with difficulties may help TAs to establish a productive teacherTA-student relationship. Furthermore, the presence of local academic staff for students' observation and evaluation seems to be necessary. 


\subsection{Implication for theory}

The theoretical contribution of this paper is an addition to the stock of cases for which activity theory can usefully be applied, demonstrating how the use of activity systems as an analytic device for in-depth analysis of multi-campus education. The activity system gave us a holistic overview and helped explain some complicated challenges.

\subsection{Implication for practice}

Having done this research, we have acquired first-hand experiences and knowledge about the challenges of offering a single campus course for more than one. The findings from this study help in offering multi-campus courses in the mentioned university as they are planning for more multi-campus courses. These findings help the university to be aware of potential challenges to try to address them well in advance. For example, by updating the rules, the university can have some training and preparation steps for the teachers and students. It will help the teachers to modify their teaching method to cover students in the remote campus. Furthermore, other higher education institutions planning to organize their education similarly may find the results useful. This is particularly relevant at this point of time after many countries have seen a wave of mergers of universities and colleges into multi-campus institutions.

\subsection{Limitations of the research}

Our research has a limitation in terms of scale, as in our case, the course was repurposed to cover only two campuses, though we believe that in case of having more campuses, some parts of findings can be generalized. Also, this research has a limitation in the size of the students' sample as 48 out of 200 students completed the online questionnaire.

\section{Conclusion}

Our study shows how repurposing a single-campus course to a multi-campus setting posed some challenges to the teacher such lack of ICT skill, lack of interaction, and by posing an extra burden. This was stressful, making the teacher lose the focus on the teaching process. Time was also wasted in dealing with technical problems and inadequate infrastructure. Besides that, students had problems with tools, and they were not properly prepared for the new setup. Technical problems distracted them from the class. Remote campus students did not have direct interaction with the teacher, so they were not deeply engaged in the lecture. The TAs, who in most cases assist with teachingrelated tasks, had to take responsibilities related to logistics and technology, spending time on the technology set up and technical failure handling. They had to have constant communication to monitor the link between campuses and to relay remote students' questions to the teacher. Technical staff faced some challenges with the new setup as 
in some cases, they did not have enough technical skills, or they lacked the right permission level.

Our research shows that multi-campus education is not just connecting two campuses by using ICT. There should be careful planning for multi-campus courses. The universities should provide clear and sufficient rules for using ICT in the classroom, particularly for multi-campus courses. The roles should be defined clearly, especially for the teacher and the TAs, so they know what to do when there are difficulties. To observe and reduce the burden of the teacher, there should be local teaching staff that students can contact in case of having difficulties with the lectures or course material. Teachers, students, TAs, and even technical staff should be prepared for the new setting. The division of work for staff should be modified if the universities want to support the multi-campus courses efficiently.

\section{References}

[1] G. R. Frederick, H. Schweizer, and R. J. C. i. t. S. Lowe, "After the in-service course: Challenges of technology integration," vol. 23, no. 1-2, pp. 73-84, 2006.

[2] K. A. Bingimlas, "Barriers to the successful integration of ICT in teaching and learning environments: A review of the literature," vol. 5, no. 3, 2009.

[3] N. Law and A. Chow, "Teacher characteristics, contextual factors, and how these affect the pedagogical use of ICT," in Pedagogy and ICT use: Springer, 2008, pp. 181-219.

[4] B. Stensaker, P. Maassen, M. Borgan, M. Oftebro, and B. J. H. E. Karseth, "Use, updating and integration of ICT in higher education: Linking purpose, people and pedagogy," vol. 54, no. 3, pp. 417-433, 2007.

[5] L. Hu and M. Webb, "Integrating ICT to higher education in China: From the perspective of Activity Theory," Education and Information Technologies, vol. 14, no. 2, p. 143, 2009.

[6] A. Cubeles and D. Riu, "The effective integration of ICTs in universities: the role of knowledge and academic experience of professors," Technology, Pedagogy and Education, vol. 27, no. 3, pp. 339-349, 2018.

[7] M. Ebden, "We're on a steep learning curve: The benefits and challenges of multi-campus university course delivery," vol. 33, pp. 267-277, 2010.

[8] A. Anderson and E. Date-Huxtable, "ICT-assisted multi-campus teaching: Principles and practice to impact equity of experience for students," Changing Demands, Changing Directions. Proceedings ascilite Hobart 2011, 2011.

[9] A. Dinye, "Managing Multi-Campus Universities in Ghana: A Comparative Analysis of University for Development Studies (Uds) and Presbyterian University College, Ghana (Pucg)," University of Ghana, 2016.

[10] M. B. Fisher and A. J. Hill, "Eportfolio Adoption and Implementation in a Multiple Campus University Environment-a Reflection on Opportunities and Challenges in Learning and Teaching at the Australian Catholic University," 2014.

[11] S. R. Cox, "Technology to enhance in-class discussions and student participation at a multicampus program," Currents in Pharmacy Teaching and Learning, 2019.

[12] R. Boyatt, M. Joy, C. Rocks, and J. Sinclair, "What (Use) is a MOOC?," in The 2nd international workshop on learning technology for education in cloud, 2014: Springer, pp. 133-145.

[13] R. L. Vines and J. Bruner, "Addressing Course Accessibility Through Collaboration and Technology," in EdMedia+ Innovate Learning, 2008: Association for the Advancement of Computing in Education (AACE), pp. 568-573. 
[14] M. Moridani, "Asynchronous video streaming vs. synchronous videoconferencing for teaching a pharmacogenetic pharmacotherapy course," American journal of pharmaceutical education, vol. 71, no. 1, p. 16, 2007.

[15] V. Kobayashi, "Transformations in Higher Education: Online Distance Learning," Educational Perspectives, vol. 35, no. 1, pp. 6-11, 2002.

[16] M. Downey and M. Brown, "The challenge of equivalence: Meshing food technology with blended learning across campuses and modes," 2009.

[17] X. Liu, "Research on science and technology innovation of multi-campus universities in China," 2007.

[18] K. Yates, M. Birks, C. Woods, and M. J. N. e. t. Hitchins, "\# Learning: The use of back channel technology in multi-campus nursing education," vol. 35, no. 9, pp. e65-e69, 2015.

[19] M. Bower, B. Dalgarno, G. E. Kennedy, M. J. Lee, J. J. C. Kenney, and Education, "Design and implementation factors in blended synchronous learning environments: Outcomes from a cross-case analysis," vol. 86, pp. 1-17, 2015.

[20] T. Andrews and G. Klease, "Challenges of multisite video conferencing: The development of an alternative teaching/learning model," Australasian Journal of Educational Technology, vol. 14, no. 2, 1998.

[21] R. Whelan, "Use of ICT in education in the South Pacific: findings of the Pacific eLearning Observatory," Distance Education, vol. 29, no. 1, pp. 53-70, 2008.

[22] R. Hjelsvold and A. Bahmani, "Challenges in Repurposing Single-Campus Courses to Multi-Campus Settings," Laring om larring, vol. 3, no. 1, 2019.

[23] S. Gërguri-Rashiti, V. Ramadani, H. Abazi-Alili, L. P. Dana, and V. J. T. I. B. R. Ratten, "ICT, innovation and firm performance: the transition economies context," vol. 59, no. 1, pp. 93-102, 2017.

[24] D. Haluza and D. Jungwirth, "ICT and the future of health care: aspects of health promotion," International journal of medical informatics, vol. 84, no. 1, pp. 48-57, 2015.

[25] D. Pederzoli, "ICT and Retail: State of the Art and Prospects," in Information and Communication Technologies in Organizations and Society: Springer, 2016, pp. 329-336.

[26] D. G. Reiss, "Is money going digital? An alternative perspective on the current hype," Financial Innovation, vol. 4, no. 1, p. 14, 2018.

[27] L. Casolaro and G. Gobbi, "Information technology and productivity changes in the banking industry," Economic Notes, vol. 36, no. 1, pp. 43-76, 2007.

[28] C. Tsolakidis, "ICT in Education: The dawn of a new era or the development of an accessory," Kefalonia, Greece: University of Aegean, 2004.

[29] A. W. Bates, Managing Technological Change: Strategies for College and University Leaders. The Jossey-Bass Higher and Adult Education Series. ERIC, 2000.

[30] J. Zhou, "A study of academic staff development in Chinese higher education institutions," King's College London (University of London), 2005.

[31] M. Carnoy, "ICT in education: Possibilities and challenges," Lección inaugural del curso académico, vol. 2005, 2004.

[32] L. Dubé, A. Bourhis, R. J. I. J. o. I. Jacob, Knowledge, and Management, "Towards a typology of virtual communities of practice," vol. 1, pp. 69-94, 2006.

[33] S. L. Groenwald, "The challenges and opportunities in leading a multi-campus university," Journal of Professional Nursing, vol. 34, no. 2, pp. 134-141, 2018.

[34] G. Harman, K. J. T. E. Harman, and management, "Institutional mergers in higher education: Lessons from international experience," vol. 9, no. 1, pp. 29-44, 2003.

[35] E. Szeto, "Bridging the Students' and Instructor's Experiences: Exploring Instructional Potential of Videoconference in Multi-Campus Universities," Turkish Online Journal of Educational Technology-TOJET, vol. 13, no. 1, pp. 64-72, 2014.

[36] M. Freeman, "Video Conferencing: a Solution to the Multi-campus Large Classes Problem?," British Journal of Educational Technology, vol. 29, no. 3, pp. 197-210, 1998. 
[37] H. Besser, "Issues and challenges for the distance independent environment," Journal of the American Society for Information Science, vol. 47, no. 11, pp. 817-820, 1996.

[38] J. R. Reilly, C. Vandenhouten, S. Gallagher-Lepak, and P. J. J. o. A. L. N. Ralston-Berg, "Faculty development for e-learning: A multi-campus community of practice (COP) approach," vol. 16, no. 2, pp. 99-110, 2012.

[39] A. Divanoglou, K. Chance-Larsen, J. Fleming, and M. J. A. J. o. E. T. Wolfe, "Physiotherapy student perspectives on synchronous dual-campus learning and teaching," vol. 34, no. 3, pp. 88-104, 2018.

[40] S. Lakhal, D. Bateman, J. J. C. E. o. L. Bédard, and Teaching, "Blended Synchronous Delivery Mode in Graduate Programs: A Literature Review and Its Implementation in the Master Teacher Program," vol. 10, pp. 47-60, 2017.

[41] J. Brick, T. d'Arbon, and J. Robson, "Putting the toe into the shark-infested waters of electronic distance education: The development of a multi campus unit and learning package using Lotus Learningspace," in Proceedings of the Australasian Society for Computers in Learning in Tertiary Education, '98 Conference, 1998, pp. 87-96.

[42] C. L. Weitze and R. Ørngreen, "The Global Classroom Model Simultaneous Campus-and Home-Based Education Using Videoconferencing," Electronic Journal of E-learning, vol. 12, no. 2, pp. 215-226, 2014.

[43] J. Buchan and M. Swann, "A bridge too far or a bridge to the future?: a case study in online assessment at Charles Sturt University," Australasian Journal of Educational Technology, vol. 23, no. 3, p. 408, 2007.

[44] A. Halabi, J. Tuovinen, and J. Maxfield, "Tele teaching accounting lectures across a multi campus: a student's perspective," Accounting Education, vol. 11, no. 3, pp. 257-270, 2002.

[45] L. S. Vygotsky, Mind in society: The development of higher psychological processes. Harvard university press, 1980.

[46] Y. Engestrom, "An activity-theoretical approach to developmental research," Learning by Expanding, 1987.

[47] V. Kaptelinin and B. Nardi, "Activity Theory as a Framework for Human-Technology Interaction Research," ed: Taylor \& Francis, 2018.

[48] K. Isssroff and E. Scanlon, "Using technology in higher education: An activity theory perspective," Journal of Computer assisted learning, vol. 18, no. 1, pp. 77-83, 2002.

[49] D. Fishman, The case for pragmatic psychology. NYU Press, 1999.

[50] C. Teddlie and A. Tashakkori, Foundations of mixed methods research: Integrating quantitative and qualitative approaches in the social and behavioral sciences. Sage, 2009.

[51] mediasite. "mediasite." https://www.mediasite.com/ (accessed 29.03.2019, 2019).

[52] B. Kaplan and D. Duchon, "Combining qualitative and quantitative methods in information systems research: a case study," MIS quarterly, pp. 571-586, 1988. 